\title{
Biocidal Mechanisms in Biological Control of Fusarium Wilt in Chickpea (Cicer arietinum L.) by Antagonistic Rhizobacteria: A Current Perspective in Soil Borne Fungal Pest Management
}

\author{
Suman Kumari ${ }^{1 *}$ and Veena Khanna ${ }^{2}$ \\ ${ }^{1}$ Department of Microbiology, ${ }^{2}$ Department of Plant Breeding and Genetics, Punjab \\ Agricultural University, Ludhiana-141004, India \\ *Corresponding author
}

\section{A B S T R A C T}

\section{Keywords}

Fusarium wilt, Antagonistic rhizobacteria, Biological control, Phytopathogens

Article Info

Accepted:

12 September 2019 Available Online: 10 October 2019
Fusarium wilt caused by Fusarium oxysporum f. sp. ciceris, one of the most important fungal pathogen of chickpea (Cicer arietinum L.), is a constant threat to this crop worldwide. It causes yield losses up to $100 \%$ depending upon the varietal susceptibility, growth stage and climatic conditions. Strategies have been employed for controlling this pathogen such as use of cultural practices, resistant cultivars, fungicides etc., but have proven less effective and even the use of chemicals have hazardous effects, and also lead to the development of fungicide resistance in pathogens. As an environmentally sound alternative, biological control is an attractive method against such soil borne diseases. Several rhizospheric bacteria have the ability to control diseases and promote the plant growth under laboratory and field conditions. Among these, species of Pseudomonas and Bacillus are the most extensively studied for the biocontrol of a variety of root associated phytopathogens. The mechanisms mainly include synthesis and release of some metabolites such as antibiotics, lytic enzymes, siderophores, hydrogen cyanide (HCN) and other diffusible and volatile antifungal compounds. All these metabolites exert inhibitory effect on a range of phytopathogens present in close vicinity of the plant roots. Moreover they provide competitive nature to these rhizobacteria for survival and function under prevalence of such soil borne fungal pathogens. Additionally, the use of antagonistic plant growth promoting rhizobacteria increase the symbiotic efficacy of indigenous Mesorhizobium ciceris present in the soil and also help in inducing the plant's own defense mechanism against several phytopathogens. Thus use of biocontrol measures using bacterial antagonists, due to their perceived level of safety; reduced environmental impact and easy delivery improve the growth and hence yield.

\section{Introduction}

Chickpea is one of the most important grain legume crops in the world, and contributes about $48 \%$ of the total pulse production in India (Anonymous, 2015). Due to its high nutritive value $(25-29 \%$ protein, $4-10 \%$ fat, $52-71 \%$ carbohydrate, and $10-23 \%$ fiber, 
minerals and vitamins) chickpea occupy an important position in the largely vegetarian population of the country (Jukanti et al., 2012; Ali and Kumar, 2006).

Amongst pulse crops, chickpea has maintained a significant status ranking second in the area and $3^{\text {rd }}$ in the production (14.6\%) (Hussain et al., 2015). This pulse crop significantly imparts the management of soil fertility primarily due to its ability to fix atmospheric nitrogen in association with the bacterial symbiont Mesorhizobium ciceri (Maiti, 2001; Kantar et al., 2007). Rhizobia offer the great advantage of symbiotic nitrogen fixation by symbiotic association with such leguminous crops (Arafoui et al., 2006).

\section{Fusarium wilt and its casual organism}

Chickpea is usually attacked by wilt caused by Fusarium oxysporum f. sp. ciceris, worldwide and is one of the consistent threats to this crop (Moradi et al., 2012). Fusarium wilt is prevalent in almost all chickpea-growing areas of the world, and resulted loss varies from $14 \%$ to $32 \%$ in the different states of India (Dubey et al., 201; Kumari and Khanna, 2014). Even this plant disease causes yield losses up to $100 \%$ under favorable conditions in chickpea (Anjaiah et al., 2003, Pande et al., 2010, Landa et al., 2004). In Pakistan it is reported that this disease incidence causes 10 to $50 \%$ loss every year (Khan et al., 2002).

Symptoms of fusarium wilt mainly include yellowing and stunting of the leaves followed by plant death in less or more susceptible chickpea cultivars and can develop at any stage of plant growth, and affected plants may be grouped in patches or appear spread throughout a field (Arafoui et al., 2006, Jiménez-Díaz et al., 2015). Severe wilt symptoms in chickpea plants mostly start to appear 25-30 days after sowing (Kumari et al., 2016). Use of pathogen free planting material, avoiding sowing into high risk soils and choice of cropping are some cultural practices to control the wilt incidence in chickpea crop (Jendoubi et al., 2016). Whereas the most efficient and reliable method of disease control and maximizing crop productivity worldwide to date has been the use of fungicides or resistant cultivars as part of an integrated management approach.

However, the high pathogenic variability and development of resistance in different populations of $F$. oxysporum presents problems for sustainability of resistant cultivars, a major constraint in developing resistant cultivars (Bayraktar and Dolar, 2012). The superiority of chemicals over biocontrol agents in terms of effective and quick disease control is well known however, the ill effects of chemicals on human health and environment are major limitations to application of chemical pesticides in the long run (Sharma, 2011). Moreover the use of agrochemical inputs causes several negative effects such as the development of pesticide resistance to applied agents and also has nontargeted environmental impacts (Gerhardson, 2002).

\section{Demand of an alternate to Chemical pesticides (Fungicides)}

Burgeoning of fungicide tolerance in pathogen strains and non-availability of fungicides along with appropriate application technologies to resource indigent farmers further reinforce the need for alternate strategies. Moreover, use of fungicides is expensive and results in accumulation of toxic compounds which adversely affects the soil biota (Jimnenez-Gasco et al., 2004). Thus, rising public concern about harmful environmental effects of agrochemicals constituted the need for greater sustainability in agriculture with alternate disease control strategies. 
Plant disease suppression by soil microorganisms is a possibly effective alternative means of reducing the chemical input in agriculture (Compant et al., 2005). Biocontrol of plant pathogenic microorganisms relies on different antagonistic traits including competition for colonization site or nutrients, production of volatile/diffusible antibiotics, enzymes and induction of systemic resistance (ISR) against the pathogens (Raaijmakers et al., 2009; Kumari and Khanna, 2016).

The strategy for control of fungal diseases of plants by the use of potential antagonistic microorganisms has been the focus of intense research throughout world. This approach is popularly known as biological control of phytopathogens and has been demonstrated to be successful in a number of host pathogen systems.

\section{Biological Control}

Biological control is an eco-friendly and potentially emerged alternative to chemical control. Soil-borne diseases have been controlled more recently by means of certain beneficial antagonistic bacteria that are indigenous to the rhizosphere of most of the plants (Compant et al., 2005; Reino et al., 2008).

The plant rhizosphere is a remarkable ecological environment as a myriad of microorganisms colonizes in, on and around the roots of growing plants. Distinct communities of beneficial soil microorganisms are associated with the root system of all higher plants (Khalid et al., 2009). These plant growths promoting rhizobacteria (PGPR) can be useful in enhancing the growth and reducing the disease severity in several agricultural crops when applied on to seed or soil (Arafoui et al., 2006; Kumari and Khanna, 2014).

\section{Plant Growth Promoting Rhizobacteria (PGPR)}

Plant growth promoting rhizobacteria (PGPR) are a group of bacteria that can be found in the rhizosphere (area under the influence of the roots), rhizoplane (at or along the root surface), in symbiotic (inside the roots) or in close association with roots. A large array of bacteria including species of Pseudomonas, Azospirillum, Azotobacter, Bacillus, Beijerinckia, Burkhoderia, Klebsiella and Serratia have shown plant growth promoting properties (Govindarajan et al., 2006; Govindarajan et al., 2007; Gyaneshwer et al., 2001). The application of PGPR in agricultural crops, offers an attractive alternative to chemical fertilizers, pesticides, and other supplements (Ashrafuzzaman et al., 2009).

These PGPR strains facilitate growth of plants either directly or indirectly. The direct mechanism of plant growth stimulation involves the production of substances by bacteria and its transport to the developing plants or facilitates the uptake of nutrients from the recipient environment. The direct growth promoting mechanisms of PGPR includes (i) Biological $\mathrm{N}_{2}$ fixation (Wani et al., 2007) (ii) solubilization of insoluble phosphorus form soil minerals (Khan et al., 2009) (iii) sequestering of iron by production of siderophores as chelating agents (Rajkumar et al., 2006) (iv) production of phytohormones such as auxins, cytokinins, gibberellins and (v) lowering of ethylene concentration to reduce the biotic and abiotic stress (Liu et al., 2007). Indirect stimulation includes the antagonistic potential to reduce the deleterious effects of plant pathogens on crop yield such as suppression of phytopathogens by producing siderophores that chelate iron making it unavailable to pathogen (Pidello, 2003), antibiotics such as Phenazine-1-carboxylic acid (PCA), Di-acety 
phloroglucinol (DAPG), Pyaocyanin etc (Chin-A-Woeng et al., 2003). Furthermore indirect mechanism also include the enhancement in the activity of phenolic compounds and pathogenesis related (PR) proteins in plants such as peroxidase (PO), polyphenol oxidase (PPO) that catalyse the formation of lignin, phenylalanine ammonialyase (PAL) that involved in formation of phytoalexins and other phenolic compounds by these rhizobacteria. Other enzymes include defense-related proteins such as $\beta-1,3-$ glucanases and chitinases which degrade the fungal cell wall and cause lysis of fungal cell (Chin-A-Woeng et al., 2003), hydrogen cyanide (HCN), ammonia etc. (Hu et al., 2005; Liu et al., 2006; Glick et al., 2007). Some Pseudomonas sp. especially fluorescent pseudomonads have been reported to be used as efficient agricultural biocontrol agents as they can produce large amount of secondary metabolites to protect plants from phytopathogens and stimulate plant growth (Arafoui et al., 2006).Thus, they are being exploited as potential biological control agents to decrease the use of chemical pesticides in agriculture.

\section{General antiphytopathogenic mechanisms of plant growth promoting rhizobateria}

Biological control of soil borne pathogens with antagonistic microorganisms has been extensively investigated. Among them, Pseudomonas and Bacillus sp. are known to increase plant growth due to production of diverse microbial metabolites like siderophore, indole acetic acid, phosphatesolubilization, hydrogen cyanide, ammonia production etc. A few strains of fluorescent Pseudomonas are also known to produce antifungal compounds that elicit induced systemic resistance in the host plant or interfere specifically with fungal pathogeniciy factors (Hass and Defago, 2005). Various mechanisms for antagonism have been implicated like cell wall degrading enzymes (pectolytic enzymes, cellulases, xylanases and glycosidic hydrolases), plant hormones (indole acetic acid, ethylene and cytokinin), siderophore which can chelate iron and other metals and contribute to disease suppression by conferring a competitive advantage to the biocontrol agent for the limited supply of essential trace minerals in natural habitats (Deshwal et al., 2003). Microbial siderophore may also stimulate plant growth directly by competitively inhibiting iron uptake system by fungal pathogen (Kravchenko et al., 2002).

Indole acetic acid (IAA), being a plant growth promoting hormone directly promotes the root growth by stimulating plant cell elongation or cell division and indirectly by influencing bacterial 1-aminocyclopropane-1- carboxylic acid (ACC) deaminase activity. ACC is the direct precursor of ethylene an inhibitor of root growth (Siddiqui and Shakeel, 2009). Arafoui et al., (2006) reported effective biocontrol of fusarium wilt of chickpea by using antagonistic Rhizobium isolates in vitro in dual culture and in vivo in field condition. Biocontrol activity and plant growth promotion of bacterial strains was evaluated under greenhouse conditions, in which $P$. aeuroginosa (P10 and $\mathrm{P} 12)$, B. subtilis (B1, B6, B28 and B99) and P. aeuroginosa (P12 and B28) provided better control than untreated control in seed treatment and soilinoculation (Karimi et al., 2012).

Additionally PGPR are also involved in increased uptake of nitrogen, solubilization of minerals such as phosphorus, zinc, potassium etc. (Siddiqui et al., 2009). Application of Bacillus, Pseudomonas and Rhizobium spp. have been reported to improve the growth of Fuasrium oxysporum infected plants by competing with the pathogen and the production of essential nutrients, enzymes, antibiotics and other organic acids to solubilise various soil minerals (Akhtar et al., 
2012; Landa et al., 2004). Plant growth promoting rhizobacteria, competitively colonize plant roots and stimulate plant growth and decrease the incident of plant diseases by some indirect mechanisms also. The PGPR mediate biological control indirectly by eliciting induced systemic resistance against a number of plant diseases (Jetiyanon and Kloepper 2002). Implementation of some PGPR strains through seed or seedling bacterization has been effectively found to lead to a state of induced systemic resistance in the treated plants (Kloepper et al., 2004).

Induced resistance is the enhancement of plants' defensive capacity against a broad spectrum of pathogens and pests that is acquired after appropriate stimulation.

The resulting elevated resistance due to an inducing agent is called induced systemic resistance (ISR) or systemic acquired resistance (SAR). Both are different in a way that Induced systemic resistance (ISR) is induced by non-pathogenic rhizobacteria, mediated by a Jasmonic acid (JA) or ethylenesensitive pathway, whereas systemic acquired resistance (SAR) is induced systemically after inoculation with necrotizing pathogens or application of some chemicals and is mediated by a salicylic acid (SA) dependent process (Zhang et al., 2010). Both SAR and ISR are the activation of latent resistant mechanisms of host plants that are expressed upon subsequent or challenge inoculation with a pathogen mainly (Vallad and Goodman, 2004). The PGPR cause plant cell wall modifications and physiological changes that lead to the synthesis of compounds involved in plant defense mechanisms (Conarth et al., 2001). Carbohydrate polymers, lipids, glycoproteins, lipopolysaccharides, siderophores and salicylic acid secreated or derived from the cell wall of PGPR are major elicitors that mediate induced systemic resistance (Antoun and Prevost, 2005). Most important bacteria studied and exploited as biocontrol agent includes the species of fluorescent Pseudomonas and Bacillus. Leguminous roots are colonized by numerous rhizospheric microorganisms and these enhance legume nitrogen fixation due to a synergism with rhizobia, thus co-inoculation of rhizobia with plant growth PGPR, is a way to improve nitrogen availability in sustainable agriculture production systems (Rajendran et al., 2012). Stimulation of nodulation and plant growth has also been reported for chickpea using Pseudomonas strains that are antagonistic to fungal pathogens (Aspergillus sp., Fusarium oxysporum, Pythium aphanidrematum and Rhizoctonia solani) as co-inoculant with Mesorhizobium and this also enhanced nodulation by $68 \%$, compared to Mesorhizobium alone (Goel et al., 2002).

Thus, identification of potential bacterial antagonists of Fusarium oxysporum and Rhizoctonia solani help to reduce the pathogenic effects and chemical inputs and such organisms can also increase the symbiotic effectiveness of Rhizobium. Bacterial antagonists isolated from the chickpea rhizosphere are also known to enhance grain yield due to their plant growth promoting potential (Whipps, 2001).

\section{Antagonistic functionality traits of rhizobacteria}

\section{Siderophore production}

Iron is the fourth most abundant element on earth (Ma 2005), however, in aerobic soils, iron is mostly precipitated as hydroxides, oxyhydroxides, and oxides so that the amount of iron available for assimilation by living organisms is very low, ranging from $10^{-7}$ to $10^{-}$ ${ }^{23} \mathrm{M}$ at $\mathrm{pH} 3.5$ and 8.5 respectively. Microorganisms have evolved specialized mechanisms for the assimilations of iron, 
including production of iron chelating compounds, known as siderophores. Siderophores are low molecular weight (500$1000 \mathrm{Da}$ ), high affinity ferric ion chelators, synthesized and secreted by many microorganisms in iron deprivation for acquisition of iron from insoluble forms by mineralization and sequestration (Sarode $e t$ al., 2009). The role of siderophores in plant growth promotion and biological control is well established (Hass and Defago, 2005).

Siderophores produced by rhizosphere inhabitants has been studied well and it has been reported that ability to produce siderophores not only improve rhizosphere colonization of producer strain but also play an important role in iron nutrition of plant (Vansuyt et al., 2007) and antagonism against phytopathogens (Chincholkar et al., 2007). Role of siderophores in induced systemic resistance (ISR) in plants is also well appreciated (Zhang et al., 2010). Improvement in plant iron nutrition by soil bacteria is even more important when the plant is exposed to an environmental stress such as heavy metal pollution (Nair et al., 2007).

The iron sequestering siderophores produced by antagonistic PGPR have a higher affinity for iron than produced by fungal pathogens, allowing the microbes to scavenge most of the available iron and thereby reduce its availability for the growth of fungal pathogen (Bashan and Bashan, 2005). The presence of siderophore-producing PGPR in rhizosphere increases the rate of $\mathrm{Fe}^{3+}$ supply to plants and therefore enhances the plant growth and productivity of crop. Iron-siderophore complex is used by plants to quench the iron thirst and this constitutes the direct plant growth promotion (Sharma and Johri, 2003). Further, this compound after chelating $\mathrm{Fe}^{3+}$ makes the soil $\mathrm{Fe}^{3+}$ deficient for other soil microbes and consequently inhibits the activity of competitive microbes (Sivaramaiah et al., 2007, Masalha et al., 2000). Siderophores are usually classified by the ligands used to chelate the ferric iron. The major groups of siderophores include the catecholates (phenolates), hydroxamates and carboxylates (Saharan and Nehra, 2011). Some examples of catecholate siderophores are the siderophore enterobactin produced by Escherichia coli, bacillibactin produced by Bacillus subtilis and Bacillus anthracis and vibriobactin produced by Vibrio cholera. Some of the examples ofhydroxamate siderophores are the ferrichromes produced by Ustilago sphaerogena, desferrioxamine B (Deferoxamine) by Streptomyces pilosus and Streptomyces coelicolor, desferrioxamine E by Streptomyces coelicolor (Prashant et al., 2009)

The ability of Pseudomonas to grow and produce siderophores is dependent on the iron content and the type of carbon sources in the medium. Low-iron concentration in soil stimulates the production and secretion of yellow-green fluorescent iron-binding peptide by Pseudomonas isolates and the biosynthesis of siderophores have also been reported to be affected by several other environmental parameters (Manwar et al., 2004). Though siderophores are part of primary metabolism (iron is an essential element), on occasions they also behave as antibiotics which are commonly considered to be secondary metabolites (Haas and Defago, 2005). Suryakala et al., (2004) has reported that siderophores exerted maximum impact on Fusarium oxysporum than on Alternaria sp. and Colletotrichum capsici. The role of microbial siderophores in N-fixation has also been implicated. Gill et al., (1991) demonstrated that mutants of Rhizobium meliloti that were unable to produce siderophore were able to nodulate the plants but the efficiency of nitrogen fixation was less as compared to the wild type indicating the importance of iron in nitrogen fixation. Another indirect mode of plant growth 
promotion is the ability of siderophore to protect from heavy metal toxicity (Glick, 2003).

Such unequivocal importance of iron in plant growth promotion and biological control encourage screening new PGPR for their ability to produce siderophores.

\section{HCN production}

Hydrogen cyanide is a broad-spectrum antimicrobial compound involved in biological control of root diseases by plant associated rhizobacteria (Ramette et al., 2003). Some rhizobacteria, including species of Alcaligenes, Aeromonas, Bacillus, Pseudomonas and Rhizobium (Devi et al., 2007; Ahmad et al., 2006) are capable of producing HCN (Rezzonico et al., 2007) which is a secondary metabolite that suppresses the growth and development of competing microorganisms (Siddiqui, 2006) as it is a powerful inhibitor of many metal enzymes, especially copper containing cytochrome c oxidases (Hassanein et al., 2009). HCN production is a common trait within the group of Pseudomonas present in the rhizosphere, with some studies showing that about $50 \%$ of pseudomonads isolated from potato and wheat rhizosphere were able to produce $\mathrm{HCN}$ in vitro (Bakker and Schippers, 1987; Schippers et al., 1990).

Hydrogen cyanide supply to the cell inhibits the electron transport thereby disrupting energy leading to the death of the pathogenic organism. It inhibits proper functioning of enzymes and natural receptors by reversible mechanism of inhibition. Antifungal activity of Pseudomonas, Bacillus and Azotobacter may be due to the production of $\mathrm{HCN}$ and siderophores or synergistic interaction of these two or with other metabolites (Ahmed et al., 2006). HCN from Pseudomonas CHAO strain not repressed by fusaric acid played a significant role in disease suppression of $F$. oxysporum f.sp. radicis-lycopersici in tomato (Duffy et al., 2003). Ramettee et al., (2003) reported that $\mathrm{HCN}$ is abroadspectrm antimicrobial compound involved in biological control of root disease by many plant associated flourescent pseudomonads.

Among the different mechanisms involved in disease suppression, the production of antimicrobial secondary metabolites such as $\mathrm{HCN}$ as well as 2,4-diacetylphloroglucinol by fluorescent Pseudomonad is reported to be of significance for effective biocontrol (Hass and Defago 2005).Direct inhibition of fungi by $\mathrm{HCN}$ is thought to be the main mechanism of action (Blumer and Hass, 2000), where the effect of bacterium would be comparable to the HCN mediated plant defense mechanisms (Luckner, 1990). It has been reported that strains of Pseudomonas producing $\mathrm{HCN}$, suppress plant disease, whereas mutant strains unable to synthesize HCN lose their ability to protect plants from phytopathogens (Sacherer et al., 1994). Siddiqui et al., (2006) found the production of $\mathrm{HCN}$ by Pseudomonas fluorescens strain $\mathrm{CHAO}$ as an antagonistic factor contributing to biocontrol of Meloidogyne javanica, a root knot nematode in situ and suppression of galling in tomato. Some strains of Pseudomonas producing HCN and antagonistic to phytopathogens have also been reported to inhibit the growth of infected plant (Kumar et al., 2005).

\section{Antibiosis}

Antibiosis plays an active role in the biocontrol of plant disease and often acts in concert with competition and parasitism. Antibiosis has been postulated to play an important role in disease suppression by rhizobacteria (Mallesh, 2008). Ahmadzadeh et al., (2006) reported that the efficient PGPR strains for antibiotic activity were selected by determining the toxicity of metabolites 
produced on pathogen by the PGPR. The synthesis of antibiotics is the mechanism that is most commonly associated with the ability of a PGPR to suppress pathogen development (Whipps, 2001).Antibiotics constitute a wide and heterogeneous group of low molecular weight chemical organic compounds that are produced by a wide variety of microorganisms (Raaijmakers et al., 2002). The antibiotics synthesized by PGPR include kanosamine, oligomycin A, 2,4-diacetylphloroglucinol, oomycin, HCN, phenazines, pyoluteorin, and pyrrolnitrin. Although the main target of these antibiotics are the electron transport chain (phenazines, pyrrolnitrin), metalloenzymes such as copper-containing cytochrome oxidases, membrane integrity (biosurfactants), their mode of action are still largely unknown (Haas and Defago, 2005; Raaijmakers et al., 2009).

The production of antibiotics is considered one of the most powerful and studied biocontrol mechanisms for combating phytopathogens. One of the most efficient antibiotics in the control of plant pathogens is 2,4-DAPG and is produced by various strains of Pseudomonas (Fernando et al., 2006; Rezzonico et al., 2007).

The most widely studied group of rhizospheric bacteria with respect to the production of antibiotics is that of the fluorescent Pseudomonads, these are known to reduce fungal growth in vitro by the production of one or more antifungal antibiotics that may also have in vivo activity (Whipps 2001).A strain of Serratia marcescens has been reported to produce antibiotics and has proven to be a useful biocontrol agent against Scleritium rolfsi and Fusarium oxysporum (Someya et al., 2002).

\section{Volatile antifungal compounds}

Plant growth promoting rhizobia can support plant growth by nitrogen fixation, secretion of phytohormones, solubilization of minerals or secretion of antibiotics and antifungal metabolites. Apart from these mechanisms it recently became apparent that microorganisms have developed another potential weapon against phytopathogens. They are capable of releasing functional volatile organic compounds (VOCs) (Kai et al., 2007; Vespermann et al., 2007; Kai et al., 2009).

Volatile organic compounds are low molecular weight compounds (below $300 \mathrm{Da}$ ), lipophilic and have relatively low boiling points. Such volatiles are ideal infochemicals as they occur in the biosphere over a range of concentrations and can act over long distances (Wheatley, 2002). Thus, these compounds have an important effect on neighboring organisms and the development of the organisms in the ecosystem. VOCs were shown to be biologically useful in numerous cases i.e. allowing pollinators to localize flowers, to attract predators of herbivores (indirect defense) or to defeat pathogens directly or to cause growth inhibition. As a result, these compounds may act inter or intraspecifically (Piechulla and Pott, 2003).

A wealth of VOCs are produced and released in the microbial world. More than 400 volatiles are known to be emitted from different bacteria (Schulz and Dickschat, 2007). Volatile compounds such as alkanes, alkenes, alcohols, aldehydes, ammonia, esters, ketones, sulfides, and terpenoids known to be produced by a number of rhizobacteria are reported to play an important role in biocontrol (El-Katatany et al., 2003).The biological significance of these microbial volatiles has been investigated. Volatiles of different soil bacteria influence the growth of various fungi (Chuankun et al., 2004; Fernando et al., 2005). Rhizobacterial isolates comprising Serratia plymuthica, Serratia odorifera, Pseudomonas fluorescens, and Pseudomonas trivialis synthesize and emit complex blends of volatiles that inhibit growth 
of manyphytopathogenic and non phytopathogenic fungi (Kai et al., 2007; Vespermann et al., 2007). Volatile compounds such as ammonia and HCN produced by a number of rhizobacteria were reported to play an important role in biocontrol. Tripathi and Johri (2002) reported that volatiles released by fluorescent Pseudomonads had significant antagonistic influence on growth of $C$. dematium and S. rolfsii. Furthermore, bacterial volatiles also have an impact on protozoa, metazoa such as nematodes, and Aedes aegypti (Kai et al., 2009).

Volatiles also play an important role in the inhibition of sclerotial activity, limiting ascospore production and reducing disease levels. In studies conducted by Hassanein et al., (2009) some toxic volatile metabolites produced by Pseudomonas aeruginosa reduced the growth of both Fusarium oxysporum and Helminthosporium sp. In another report bacteria isolated from soybean plants produced antifungal organic volatile compounds, these compounds inhibited sclerotia and ascospore germination and mycelia growth of Sclerotinia sclerotium in vitro and in soil tests (Fernando et al., 2005). Bacillus species exhibiting antifungal potential have a wide range of antimicrobial activities that inhibit mycelia growth of Fusarium oxysporum with the highest effect in reducing fusarium wilt of onion (Wahyudi et al., 2011). This compound has the ability of degrading cell walls of soil-borne fungal pathogen (ElTarabily et al., 2000). Bapat and Shah (2000) reported that Bacillus brevis which produced an extracellular antagonistic metabolite inhibited germination of conidia and was fungicidal to the vegetative mycelia of Fusarium oxysporum sp.udum. Yiu-K-wok et al., (2003) emphasized that Bacillus subtilis filtrate was active at different dilutions against macroconidium germination and hyphal growth of Fusarium graminearum depending on the initial macroconidium density. Interest is focused on the qualitative and quantitative composition as well as on the timing of volatile emissions.

\section{Diffusible antifungal compounds}

Endophytic microorganisms have attracted the attention of researchers because of their potential to serve as biocontrol agents as they are able to produce a number of secondary metabolites to inhibit pathogens (Ryan et al., 2008). Antibiotics produced by PGPR include phenazine, pyoluteorin, pyrrolnitrin and cyclic lipopeptides all of which are diffusible (Haas and Defago, 2005). Certain PGPR degrade fusaric acid produced by Fusarium sp. causative agent of wilt and thus prevents the pathogenesis. Some PGPR can also produce enzymes that can lyse cells and are diffusible. Pseudomonas stutzeri produces extracellular chitinase and laminarinase which could lyse the mycelia of Fusarium solani (Isnansetyo et al., 2003).

Phenazine is a potent green pigmented antimicrobial metabolite implicated in antagonism (Tjeerdvan et al., 2004). It is nitrogen containing low molecular weight antimicrobial compound consisting of brightly coloured pigment produced by the bacterial genera pertaining to Pseudomonas, Burkholderia, Brevibacterium and Streptmyces (Fernando et al., 2005). The ability to produce phenazines is limited almost exclusively to bacteria and has been reported in members of the genera Pseudomonas, Streptomyces, Nocardia, Sorangium, Brevibacterium and Burkholderia (Mavrodi et al., 2006).

Flourescent Pseudomonas and Bacillus species play an active role in suppression of pathogenic microorganisms by the secretion of extracellular metabolites that are inhibitory at low concentration such as phenazine derivatives. Pseudomonas fluorescens 
producing DAPG have been recovered from soil and rhizosphere samples of many crop species as well as from marine environments (Fuente et al., 2004; Isnansetyo et al., 2003). In addition to their antifungal activity, such bacteria have been found to possess some antiviral properties and also inhibit the growth of soft-rotting bacteria and cyst nematodes of potato (Cronin et al., 1997) due to presence of DAPG. Xiang-Tian Yin et al., (2011) isolated B. amyloliquefaciens strain PEBA20 from poplar and reported its potential against poplar canker caused by $B$. dodhidea. Sharma and Parihar (2010) reported in their investigations, the ability of extracellular antifungal metabolites of Actinomycetes against Rhizopus stolonifer, Aspergillus flavus, F.oxysporum and Alternaria sp. Even under these low concentrations circumstances if the antibiotic producers are able to control plant diseases it may be due to the involvement of systemic resistance mediated by the antibiotics at very low concentration or due to the interaction of antibiosis with other extra cellular metabolites that may trigger ISR. According to a study by Küçük and Kivanç (2003), avoiding direct contact with an antagonist has given the pathogen an opportunity for greater development. However it has also shown that $T$. harzianum expresses reducing effect over both volatile and diffusible metabolites and have more reducing effect than volatiles ones (Ryan et al., 2008).

\section{Induction of Pathogenesis related (PR) proteins}

The utilization of a plant's own defense mechanism is the subject of current interest in the management of pests and diseases. Induction of plant defense genes by prior application of inducing agents is called induced resistance (Saravanakumar et al., 2007).The defense gene products include peroxidase (PO), polyphenol oxidase (PPO) that catalyze the formation of lignin and phenylalanine ammonia-lyase (PAL) that is involved in phytoalexin and phenolics biosynthesis. Other defense enzymes include PR proteins such as $\beta$-1,3-glucanases and chitinases which degrade the fungal cell wall. Chitin and glucanoligomers released during degradation of fungal cell wall act as elicitors of various defense mechanisms in the plants (Sateesh et al., 2004).Induction of defense enzymes makes the plant resistant to pathogen invasion. Excellent inducers include pathogens, non-pathogenic PGPR, chemicals and plant products (Ramamoorthy et al., 2002). The induced protection by selected strains of non-pathogenic, root-colonizing PGPR has been shown to be capable of inducing disease resistance in addition to promoting plant growth.

Plant growth promoting rhizobacteria, especially Pseudomonas fluorescens and Bacillus subtilis, are promising candidates of biological control. In a study, P. fluorescens (Pf1 and Py15) and B. subtilis (Bs16) strains have been developed commercially as a talcbased formulation and tested against several crop diseases (Vivekananthan et al., 2004, Kavino et al., 2007; Thilagavathi et al., 2007). Investigations on mechanisms of disease suppression by plant products and PGPR reveal that these may either act on the pathogen directly (Amadioha, 2000), or induce systemic resistance in host plants resulting in reduction of disease development (Ramamoorthy et al., 2002).

Systemic resistance (ISR) induced by Bacillus and Pseudomonas sp. activate multiple defense mechanisms that include increased activity of pathogenesis related (PR) proteins like chitinase, $\beta$-1,3-glucanase and peroxidase (PO), and also the accumulation of low molecular weight substances called phytoalexins (Vivekananthan et al., 2004). Chitinases and $\beta$-1,3-glucanases are a structurally and functionally diverse group of 
hydrolytic enzymes involved in defense reactions of plants against pathogens (Rajendran et al., 2007).

As far as chickpea is concerned, different investigations have shown that induced resistance, through the accumulation of various phenolic compounds and phytoalexins, synthesis of pathogenesisrelated proteins as well as the activation of different enzymes such as chitinases, $\beta-1,3$ glucanases, peroxidases, polyphenol oxidases and key enzymes in phenylpropanoid and isoflavonoid pathways, may play a crucial role in the biological control of chickpea diseases by antagonistic microorganisms (Arafaoui et al., 2006).

With increasing awareness about the adverse effects of chemical fertilizers and pesticides, it is very important to explore various mechanisms by which plant growth promoting microorganisms can control the phytopathogenic effects in the crop plants. Plant growth promoting rhizobacteria can be used as an effective biofungicide on the condition of their effectiveness under field conditions, against such soil borne fungal phytopathogens. Further investigations need to focus on enhancing the self defence mechanism of plants by these antagonistic rhizobacteria and to evaluate the synergistic potential of antagonists to formulate various combinations of these so as to have better results against such soil borne phytopathogens.

\section{References}

Ahmadzadeh, M., Afsharmanesh, H., Mohammad, J. N., Tehrani, A. S. 2006. Identification of some molecular traits in fluorescent Pseudomonad with antifungal activity. Iranian J Biotech. 4(4): 276-90.

Ahmed, F., Ahmed, I., and Khan, N. S. 2006 Screening of free-living rhizobacteria for their multiple plant growth promoting activities. Microbiological Research. 12: 245-256.

Akhtar, A., Hisamuddin, Robab, M. I., Abbasi, and Sharf, R. 2012 Plant growth promoting Rhizobacteria: An overview. J Nat Prod Pl Resour. 2(1): 19-31.

Ali, M., and Kumar, S. 2006. Pulse production in India. Yojana Pp. 13-15

Amadioha, A. C., 2000. Controlling rice blast in vitro and in vivo with extracts of Azadirachta indica. Crop Protection. 19: 287-290.

Anjaiah, V., Cornelis, P., Koedam, N., 2003. Effect of genotype and root colonization in biological control of fusarium wilts in pigeonpea and chickpea by Pseudomonas aeruginosa PNA1. Canadian Journal of Microbiology. 49(2): 85-91.

Anonymous., 2015. Commodity profile of pulses March 2015. Department of Agriculture and Co-operation, Ministry of Agriculture, Government of India

Antoun H., and Prévost, D. 2005. Ecology of plant growth promoting rhizobacteria. PGPR: Biocont Biofert 3: 1-38.

Arafoui A., Sifi B., Boudabous A., Hadrami, I. E., and Cherif, M. 2006. Identification of Rhizobium isolates possessing antagonistic activity against Fusarium oxysporum f. sp. ciceris, the causal agent of fusarium wilt of chickpea. Journal of Plant Pathology. 88: 67-75.

Ashrafzzaman, M., Hossen, F., Razi, Ismail, M., Anamul, H. M., Zahurul, I. M., Shahidullah, S. M., Meon S 2009. Efficiency of plant growth-promoting rhizobacteria (PGPR) for the enhancement of rice growth. African Journal of Biotechnology 8(7): 1247-1252.

Bakker, A.W., and Schippers, B. 1987. Microbial cyanide production in the rhizosphere in relation to potato yield reduction and Pseudomonas spp. mediated plant growth stimulation. Soil Biol Biochem. 19: 249256.

Bapat, S., and Shah, A. K. 2000. Biological control of fusarium wilt of pigeon pea by Bacillus brevis. Can J Microbiol. 46: 125132.

Bashan, Y., and Bashan, L. E. 2005 In: Encyclopedia of soils in the environment. Springer Verlag, Germany Pp. 103-115. 
Bayraktar, H., and Dolar, F. S., 2012. Pathogenic variability of Fusarium oxysporum f. sp. ciceris isolates from chickpea in Turkey. Pakistan J Bot 44: 821-823.

Blumer, C., and Haas, D. 2000 Mechanism, regulation, and ecological role of bacterial cyanide biosynthesis. Arch Microbiol 173: 170-177.

Chin-A-Woeng, T. F., Bloemberg, G.V., and Lugtenberg, B. J. 2003 Phenazines and their role in biocontrol by Pseudomonas bacteria. New Phytol. 157:503-523

Chincholkar, S. B., Chaudhari, B. L., and Rane, M. R. 2007. Microbial Siderophores: State of art. In:Microbial Siderophores, Chincholkar S B and Varma A (ed) Springer Verlag, Germany, Pp. 233-242.

Chuankun, X., Minghe, M., Leming, Z., and Kegin, Z, 2004. Soil volatile fungistasis and volatile fungistatic compounds. Soil Biol Biochem. 36: 1997-2004.

Compant, S., Duffy, B., Nowak, J, Clement, C., and Barka, E. A., (2005) Use of plant growth-promoting bacteria for biocontrol of plant diseases: principles, mechanisms of action, and future prospects. Appl Environ Microbiol 71: 4951-4959.

Conrath, U., Thulke, O., Katz, V., Schwindling, S., and Kohler, A. 2001. Priming as a mechanism in induced systemic resistance of plants. Eur J Plant Pathol 107:113-119.

Cronin, D. Y., Moënne-Loccoz, Fenton, A., Dunne, C., Dowling, D. N., O'Gara, F. 1997. Role of 2, 4-diacetylphloroglucinol in the interaction of the biocontrol pseudomonad strain F113 with the potato cyst nematode Globodera rostochiensis. Appl Environ Microbiol. 63: 1357-1361.

Deshwal, V. K., Pandey, P., Kang, K. C., and Maheshwari, D. K. 2003. Rhizobia as biological control against soil-borne plant pathogenic fungi. Ind J Exp Biol. 41: 1160-1164.

Devi, K. K., Seth, N., Kothamasi, S., Kothamasi, D. 2007. Hydrogen cyanide-producing rhizobacteria kill subterranean termite Odontotermes obesus (Rambur) by cyanide poisoning under in Vitro Conditions. Curr Microbiol. 54: 74-78.

Dubey, S. C., Singh, S. R., Singh, B. 2010. Morphological and pathogenic variability of Indian isolates of Fusarium oxysporum f. sp. ciceri causing chickpea wilt. Arch Phytopathol 43: 174-190.

Duffy, B., Schouten, A., Raajimakers, J. 2003. Pathogen self-defense: mechanisms to counteract microbial antagonism. Ann Rev Phytopathol 45: 501-538.

El-Katatany M., Hetta, A., Sliaban, G., El-Komy, H. 2003. Improvement of cell wall degrading enzymes production by alginate encapsulated Trichoderma sp. Food Technol Biotechnol 41: 219-225.

El-Tarabily, K. A., Soliman, M. H., Nasar, A. H., Al, Hasanai, H. A., Sivaithamparam, K., McKenna, F., and Hardy, G. E. (2000) Biological control of Sclerotium minor using a chitinolytic bacterium and and actinomycetes. Plant Pathology. 49(5) : 573-583

Fernando, W. G. D., Nakkeeran, S., and Zhang, Y. 2006. Biosynthesis of antibiotics by PGPR and its relation in biocontrol of plant diseases. In: Siddiqui $\mathrm{Z}$ A (ed).PGPR: Biocontrol and Biofertilization. Springer, Netherlands, Pp: 67-109.

Fernando, W. G. D., Ramarathan, R., Krishnamoorthy, A. S. and Savchuk, S. C. 2005. Identification and use of potential bacteria organic antifungal volatile isolates in biocontrol. Soil Biol Biochem 37: 955964.

Fuente, D. L. L., Thomashow, L. S., Weller, D. M., Bajsa, N., Quagliotto, L., Chernin, A. 2004. Pseudomonas fluorescens UP61 isolated from birds foot trefoil rhizosphere produces multiple antibiotics and exerts a broad spectrum of biocontrol activity. Eur J Pl Pathol 110: 671-681.

Gerhardson, B., (2002) Biological substitutes for pesticides. Trends Biotechnol 20(8): 338343.

Gill, P. R., Bartoa, L. L., Scoble, M. D., Neilands, J. B. 1991. A high affinity iron transport system of Rhizobium meliloti may be required for $\mathrm{N}$-fixation in plants. In: Chen $\mathrm{Y}$ and Hader $\mathrm{Y}$ (ed.), Iron nutrition and interactions in plants. Kleewer Academic Publishers, the Netherlands. Pp. 251-257.

Glick, B. R., 2003. Phytoremediation: Synergistic use of plants and bacteria to clean up the environment. Biotechnol Adv. 21: 383- 
393.

Glick, B. R., Cheng, Z., Czarny, J., Duan, J. 2007. Promotion of plant growth by ACC deaminase-producing soil bacteria. Eur $\mathbf{J}$ Plant Pathol. 119: 329-339.

Goel, A. K., Sindhu, S. S., Dadarwal, K. R., 2002. Stimulation of nodulation and plant growth of chickpea (Cicer arietinum L.) by Pseudomonas spp. antagonistic to fungal pathogens. Biol Fertil Soils. 36: 391-396.

Govindarajan, M., Kwon, S. W., Weon, H. Y. 2007. Isolation, molecular characterization and growth-promoting activities of endophytic sugarcane diazotroph Klebsiella sp. GR9.World J Microbiol Biotechnol. 23: 997-1006

Govindarajan, M., Revathi, G., and Lakshminarasimhan, C. 2006. Improved yield of micropropagated sugarcane following inoculation by endophytic Burkhoderia vietnamiensis. Pl Soil 280: 239-52.

Gyaneshwar. P., James, E. K., Mathan, N., Reddy, P. M., Reihold-Hurek, V., Ladha, J. K. 2001. Endophytic colonization of rice by a diazotrophic strains of Serratia marcescens. J Bacteriol 183: 2634-45.

Hass, D., and Defago, G. 2005. Biological control of soil borne pathogens by fluorescent Pseudomonad. Nat Rev Microbiol 3: $307-$ 319.

Hassanein, W. A., Awny, N. M., El-Mougith, A. A., and Salah, El-Dien, S. H. 2009. The antagonistic activities of some metabolites produced by Pseudomonas aeruginosa Sha8. J Appl Sci. 5: 404-14.

Hu, H. B., Xu, Y. Q., Cheng, F., Zhang, X. H., and Hur, B. 2005. Isolation and characterisation of a new Pseudomonas strain produced both phenazine 1carboxylic acid and pyoluteorin. J Microb Biotech 15: 86-90.

Hussain, N., Aslam, M., Ghaffar, A., and Irshad, M. 2015. Chickpea genotypes evaluation for morphoyield traits under water stress conditions. J Anim Plant Sci 25: 206-211.

Isnansetyo A, Cui L, Hiramatsu K, Kamei Y (2003) Antibacterial activity of 2,4 diacetylphloroglucinol (DAPG) produced by Pseudomonas sp. AMSN isolatsed from a marine alga, against vancomycin- resistant Staphylococcus aureus (VRSA). Int J Antimicrob Agents 22: 545-547.

Jendoubi, W., Bouhadida, M., Boukteb, A., Béji, M. and Kharrat, M. 2017. Fusarium Wilt Affecting Chickpea Crop. Agriculture. $7(23): 1-16$

Jetiyanon, K., and Kloepper, J. W. 2002. Mixtures of plant growth-promoting rhizobacteria for induction of systemic resistance against multiple plant diseases. Biol Control. 24: 285-291.

Jiménez-Díaz, R. M., Castillo, P., del Mar, Jiménez-Gasco, Landa, M., and NavasCortés, B. B., 2015. Fusarium wilt of chickpeas: Biology, ecology and management. Crop Prot. 73: 16-27.

Jimnenez-Gasco, M. M., Navas-Cortes, J. A., and Jimnez-Diaz, R. M. 2004. The Fusarium oxysporum f. sp. ciceris pathosystems: a case study of evolution of plantpathogenic fungi into races and pathogens. Int Microbial. 7: 95-104.

Jukanti, A.K., Gaur, P.M., Gowda, C. L. L., and Chibbar, R. N. 2012. Chickpea: nutritional properties and its benefits. The British Journal of Nutrition. 108:11-26.

Kai, M., Effmert, U., Berg, G., and Piechulla, B. 2007. Volatiles of bacterial antagonists inhibit mycelial growth of the plant pathogen Rhizoctonia solani. Arch Microbiol. 187: 351-60.

Kai, M., Haustein, M., Molina, F., Petri, A., Scholz, B., and Piechulla, B. 2009. Bacterial volatiles and their action potential. Appl Microbiol Biotechnol. 81: 1001-1012.

Kantar, F., Hafeez, F. Ye., Shivkumar, B. G., Sundarm, S. P., Tejera, N. A., Aslam, A. B., and Raja, P. 2007. Chickpea: Rhizobium Management and Nitrogen Fixation. Chickpea Breeding and Management Pp. 179-194.

Karimi, K., Amini1, J., Harighi, B., and Bahramnejad, B. 2012. Evaluation of biocontrol potential of Pseudomonas and Bacillus spp. against Fusarium wilt of chickpea. Afric J Biotech. 11(16): 37583765.

Kavino, M., Harish, S., Kumar, N., Saravanakumar, D., Domodaran, T., Soorianasundaram, K., and Samiyappan, R. (2007) Rhizosphere 
and endophytic bacteria for induction of systemic resistance of banana plantlets against bunchy top virus. Soil Biol Biochem 39: 1087-1098.

Khalid, A., Arshad, M., Shaharoona, B. and Mahmood, T. 2009. Plant growth promoting rhizobacteria (PGPR) and sustainable agriculture. In: Khan M S, Zaidi A and Musarat J (Ed). Microbial Strategies for Crop Improvement. Springer-Verleg, Germany Pp. 133-160.

Khan, I. A., Alam, S. S., Haq, A., and Jabbar, A. 2002. Selection for resistance to wilt and its relationship with phenols in chickpea. Int Chickpea and Pigeonpea Newslet. 9:19-20.

Khan, M. S., Zaidi, A., Wani, P. A., Ahemad, M., and Oves, M. 2009. Functional diversity among plant growth-promoting rhizobacteria. Microbial Strategies Crop Improvement. pp. 105-132.

Kloepper, J. W., Ryu, C. M., and Zhang, S. 2004. Induced systemic resistance and promotion of plant growth by Bacillus spp. Phytopathol 94: 1259-1266

Kravchenko, L. V., Makarova, N. M., Azarova, T. S., Provorov, N. A., Tikhonovich, I. A. 2002. Isolation and phenotypic characteristics of growth-stimulating rhizobacteria (PGPR), with high rootcolonizing and phytopathogenic fungi inhibiting abilities. Microbiol. 71(4): 521525.

Küçük, C., and Kivanç, M. 2003. Isolation of Trichoderma spp. and determination of their antifungal, biochemical and physiological features. Turk J Biol. 27: 247-253

Kumar, S. R., Ayyadurai, N., Pandiaraja, P., Reddy, A. V., Venkateswarlu, Y., Prakash, O., and Sakthivel, N. 2005. Characterization of antifungal metabolite produced by a new strain of Pseudomonas aeruginosa $\mathrm{PUPa} 3$ that exhibits broad spectrum antifungal activity and biofertilizing traits. J Appl Microbiol. 98: 145-154.

Kumari, S., and Khanna, V. 2014. Effect of antagonistic rhizobacteria coinoculated with Mesorhizobium ciceris on control of fusarium wilt in chickpea (Cicer arietinum
L.). Afric J Micro Res. 8(12): 1255-1265.

Kumari, S., Khanna, V., and Sharma, P. 2016. Induction of systemic resistance and wilt management in chickpea by antagonistic rhizobacteria co-inoculated with Mesorhizobium ciceris. Int J Adv Res. 4(6): 1553-1562

Landa, B. B., Navas-Cortes, J. A., and IimenezDiaz, R. M. 2004. Integrated management of Fusarium wilt ofchickpea with sowing date, host resistance and biological control. Phytopathol. 94: 946-960.

Liu, H. M., Dong, D. X., Peng, H. S., Zhang, X. H., and $\mathrm{Xu}, \mathrm{Y}$. Q. 2006. Genetic diversity of phenazine- and pyoluterin-producing pseudomonads isolated from green pepper rhizosphere. Arch Microbial 185: 91-98.

Liu, H., He, Y., Jiang, H., Peng, H., and Huang, X. 2007. Characterization of a phenazineproducing strain Pseudomonas chlororaphis GP72 with broad-spectrum antifungal activity from green pepper rhizosphere. Curr Microbiol. 54: 302-306

Luckner, M., 1990. Secondary products derived from amino acids. In: secondary metabolites in microorganisms, plants, animals. Springer-Verlag. Berlin, Germany, Pp. 246-249.

Ma, J. F., 2005. Plant root responses to three abundant soil minerals: silicon, aluminum and iron. Crit Rev Pl Sci. 24: 267-281.

Maiti, R. K., 2001. The chickpea crop. In:Maiti R and Wesche-Ebeling $\mathrm{P}$ editors. Adv Chickpea Sci. Science Publishers Inc. Pp.1-31.

Mallesh, S. B., 2008. Plant growth Promoting Rhizobacteria, their characterization and mechanisms in the suppression of soil borne pathogens of Coleus and Ashwagandha. M.Sc. thesis, University of Agricultural Sciences, Dharwad, India.

Manwar, A. V., Khandelwal, S. R., Chaudhari, B. L., Meyer, J. M., and Chincholkar, S. B., 2004. Siderophore production by a marine Pseudomonas aeruginosa and its antagonistic action against phytopathogenic fungi. App Biochem Biotechnol. 118: 243-252.

Masalha, J. H., Kosegarten, O., Elmaci, and Mengel, K., 2000. The central role of microbial activity for iron acquisition in 
maize and sunflower. Biol Fert Soils. 30: 433-439.

Mavrodi, O. V., Mavrodi, D. V., Park, A. A., Weller, D. M., and Thomashow, L. S., 2006. The role of dsbA in colonisation of wheat rhizosphere by Pseudomonas fluorescens Q8r1-96. Microbiol 152: 863872.

Moradi, H., Bahramnejad, B., Amini, J., Siosemardeh, A., and HajiAllahverdipoor, K., 2012. Suppression of chickpea (Cicer arietinum L.) Fusarium wilt by Bacillus subtillis and Trichoderma harzianum. POJ 5(2): 68-74.

Nair, A., Juwarkar, A. A., and Singh S. K. 2007. Production and characterization of siderophores and its application in arsenic removal from contaminated soil. Water Air Soil Pollut. 180: 199-212.

Pande, S., Desai, S., and Sharma, M. 2010. Impacts of climate change on rainfed crop diseases: Current Status and Future Research Needs. National Symposium on Climate Change and Rainfed Agriculture, Hyderabad, 18(20): 55-59.

Pidello, A., 2003. The effect of Pseudomonas fluorescens strains varying in pyoverdine production on the soil redox status. Pl Soil. 253: 373-379.

Piechulla, B., and Pott, M. B., 2003. Plant scentsmediator of inter- and intraorganismic communication. Planta. 217: 687-689.

Prashant, S. D., Rane, M. R., Chaudhari, B. L., Chincholkar, S. B. 2009. Siderophoregenic Acinetobacter calcoaceticus isolated from wheat rhizosphere with strong PGPR activity. Mal J Microbiol. 5(1): 6-12.

Raaijmakers, J. M., Paulitz, T. C., Steinberg, C., Alabouvette, C., and Moe"nne-Loccoz, Y. 2009. The rhizosphere: a playground and battlefield for soilborne pathogens and beneficial microorganisms. Pl Soil. 321: 341-361.

Raaijmakers, J. M., Vlami, M., De, Souza, J. T. 2002. Antibiotic production by bacterial biocontrol agents. Antonie Leeuwenhoek. 81(28): 537-547.

Rajendran, G., Patel, M. H., Joshi, S. J. 2012. Isolation and Characterization of Nodule Associated Exiguobacterium sp. from the Root Nodules of Fenugreek (Trigonella foenum-graecum) and their possible role in plant growth promotion. Int J Microbiol Pp 1-8.

Rajendran, L., Samiyappan, R., Raguchander, T., Saravanakumar, D. 2007. Endophytic bacteria mediate plant resistance against cotton bollworm. J Pl Interact. 2: 1-10.

Rajkumar, M., Nagendran, R., Wang, L. J. K., Zoo, H. L., and Kim, S., 2006. Influence of plant growth promoting bacteria and $\mathrm{Cr}^{6+}$ on the growth of Indian mustard. Chemosphere. 62: 741-748.

Ramamoorthy, V., Raguchander, T., and Samiyappan, R., 2002. Induction of defense related proteins in tomato roots treated with Pseudomonas fluorescens Pf1 and Fusarium oxysporum f. sp. lycopersici. Pl Soil. 239: 55-68.

Ramette, A., Frapolli, M., defado, G., MoenneLoccoz, Y., 2003. Phylogeny of HCN synthase-encoding hcnBC genes in biocontrol fluorescent Pseudomonad and its relationship with host plant species and HCN synthesis ability. Amer Phytopathol Soc. 16: 525-535.

Reino, L. R., Raul, F., Herna’ndez-Gala'n, G. R., and Collado, I. G. 2008. Secondary metabolites from species of the biocontrol agent. Trichoderma. Phytochem. 7: 89123

Rezzonico, F., Zala, M., Keel, C., Duffy, B., Moénne-Loccoz, Y., and Défago, G., 2007. Is the ability of biocontrol fluorescent pseudomonads to produce the antifungal metabolite 2,4diacetylphloroglucinol really synonymous with higher plant protection. New Phytol 173: 861-872.

Ryan, R. P., Fouhy, Y., and Garcia, B.F. 2008. Interspecies signaling via the Stenotrophomonas maltophilia diffusible signal factor influences biofilm formation and polymyxin tolerance in Pseudomonas aeruginosa. Mol Microbiol. 68: 75-86.

Sacherer, P., Defago, G., and Hass, D. 1994. Extracellular protease and phospholipase $\mathrm{C}$ and controlled by the global regulatory gene gacA in the biocontrol strain Pseudomonas fluorescence CHAO. FEMS Microbiol Lett. 116: 155-60.

Saharan, B. S., and Nehra, V. 2011. Plant Growth 
Promoting Rhizobacteria: A Critical Review. LSMR. 21: 1-30.

Saravanakumar, D., Vijayakumar, C., Kumar, N., and Samiyappan, R., 2007. PGPR induced defense responses in the tea plant against blister blight disease. Crop Prot. 2: 556565.

Sarode, P. D., Rane, M. R., Chaudhari, B. L., Chincholkar, S. $\quad$ B., 2009. Siderophoregenic Acinetobacter calcoaceticus isolated from wheat rhizosphere with strong PGPR activity. Malayas J Microbiol. 5(1): 6-12.

Sateesh, K., Marimuthu, T., Thayumanavan, B., Nandakumar, R., Samiyappan, R. 2004. Antimicrobial activity and induction of systemic resistance in rice by leaf extract of Datura metel against Rhizoctonia solani and Xanthomonas oryzae pv. oryzae. Physiol Mol Pl Pathol 65: 91-100.

Schippers, B., Bakker, A. W., Bakker, P. A. H. M., Van, P. R., 1990. Beneficial and deleterious effects of HCN-producing pseudomonads on rhizosphere interactions. Pl Soil. 129: 75-83.

Schulz, S., and Dickschat, J. S. 2007. Bacterial volatiles: the smell of small organisms. Nat Prod Rep. 24: 814-42.

Sharma, A., and Johri, B. N., 2003. Combat of iron-deprivation through a plant growth promoting fluorescent Pseudomonas strain GRP3A in mung bean, (Vigna radiata L. wilzeck). Microbiol Res. 158: 77-81.

Sharma, H., Parihar, L. 2010. Antifungal activity of extracts obtained from Actinomycetes. J Yeast Fungal Res. 1(10): 197-200.

Sharma, P., 2011. Evaluation of disease control and plant growth promotion potential of biocontrol agents on Pisum sativum and comparison of their activity with popular chemical control agent - carbendazim. J Toxicol Environ Health Sci. 3(5): 127138.

Siddiqui, Z. A., 2006. PGPR: Prospective Biocontrol Agents of plant Pathogens. In: Siddiqui Z A (ed) PGPR: Biocont and Biofert Springer, Dordrechet, The Netherlands. Pp.111-142

Siddiqui, Z. A., and Shakeel, U. 2009. Biocontrol of wilt disease complex of pigeon pea (Cajanus cajan (L.) Millsp.) by isolates of
Pseudomonas spp. Afr J PI Sci. 3(1): 1-12. Sivaramaiah, N., Malik, D. K., and Sindhu, S. S. 2007. Improvement in symbiotic efficiency of chickpea (Cicer arietinum) by co-inoculation of Bacillus strains with Mesorhizobium sp. cicer. Ind J Microbiol 47: 51-56.

Someya, N., Nakajima, M., Hidi, T., Yamaguchi, I., and Akutsu, K., 2002. Induced resistance to rice blast by antagonistic bacterium, Serratia marcescens B2. J Gen Pl Pathol. 68: $177-82$.

Suryakala, D., Maheshwaridevi, P. V., and Lakshmi, K. V. 2004 Chemical characterization and in vitro antibiosis of siderophores of rhizosphere fluorescent pseudomonads. Ind J Microbiol. 44: 105108.

Thilagavathi, R., Saravanakumar, D., Ragupathi, N., Samiyappan, R. 2007. A combination of biocontrol agents improves the management of dry root rot (Macrophomina phaseolina) in greengram. Phytopathologia Mediterranea. 46(2): 157-167.

Tjeerdvan, R. E., Wesselink, M., Thomas, F. C., Chin, A. W., Bloemberg, G. V., and Lugtenberg, J. J., 2004. Influence of environmental condition on the production of phenazine-1-carboxamide by Pseudomonas chlororaphis strain PCL1391. Mol Pl Microb Int. 17: 557566.

Tripathi, M., and Johri, B. N. 2002. In vitro antagonistic potential of fluorescent Pseudomonas and control of sheath blight of maize caused by Rhizoctonia solani. Ind J Microbiol. 42: 207-214.

Vallad, G. E., and Goodman, R.M. 2004. Systemic acquired resistance and induced systemic resistance in conventional agriculture. Crop Sci. 44:1920-1934.

Vansuyt, G., Robin, A., Briat, J. F., Curie, C., and Lemanceau, P. 2007 Iron acquisition from Fe pyoverdine by Arabidopsis thaliana. Mol Pl Microb Int. 20: 441-47.

Vesperman, A., Kai, M., and Piechulla, B. 2007. Rhizobial volatiles affect the growth of fungi and Arabidopsis thaliana. Appl Environ Microbiol. 73: 5639-5641.

Vivekananthan, A., and Samiyappan, R. 2004. 
Lytic enzymes induced by Pseudomonas fluorescens and other biocontrol organisms mediate defence against the anthracnose pathogen in mango. World $\mathrm{J}$ Microbiol Biotechnol 20: 235-244.

Vivekananthan, R., Ravi, M., Raman, Rajendran, L., Samiyappan, R., Raguchander T, Saravanakumar D (2007) Endophytic bacteria mediate plant resistance against cotton bollworm. J Pl Interact. 2: 1-10.

Wahyudi, A. T., Astuti, R. P., Widyawati, A., Meryandini, A. and Nawangsih, A. A. (2011) Characterization of Bacillus sp. strains isolated from rhizosphere of soybean plants for their use as potential plant growth for promoting rhizobacteria. J Microbiol Antimicrob. 3(2): 34-40.

Wani, P. A., Khan, M. S., and Zaid, A. (2007) Co inoculation of nitrogen fixing and phosphate solubilizing bacteria to promote growth, yield and nutrient uptake in chickpea. Acta Agron Hungarica. 55: 315323.

Wheatley, R. E., 2002. The consequences of volatile organic compound mediated bacterial and fungal interactions. Antonie Leeuwenhoek. 1: 357-64.

Whipps, J. M., 2001. Microbial interaction and biocontrol in the rhizosphere. J Exp Bot. 52: 487-511.

Xiang-Tian, Y., Li-Na, X., Liang, X., Su-Su, F., Zhen-Yu, Liu, Xing-Yao, Zhang, 2011. Evaluation of the efficacy of endophytic Bacillus amyloliquefaciens against Botryosphaeria dothidea andother phytopathogenic microorganisms. Afr J Microbiol Res. 5(4): 340-345.

Yiu-K-wok, C., Wayne, A., McCormic, K., Keith, A. S., 2003. Characterization of antifungal soil bacterium and its antifungal activities against Fusarium sp. Can J Microbiol. 49: 253-262.

Zhang, S., White, T. L., Martinez, M. C., Mcinroy, J. A., Kloepper, J. W. 2010. Evaluation of plant growth promoting rhizobacteria for control of Phytopathora blight on squash under greenhouse conditions. Biol Control. 53: 129-135.

\section{How to cite this article:}

Suman Kumari and Veena Khanna. 2019. Biocidal Mechanisms in Biological Control of Fusarium Wilt in Chickpea (Cicer arietinum L.) by Antagonistic Rhizobacteria: A Current Perspective in Soil Borne Fungal Pest Management. Int.J.Curr.Microbiol.App.Sci. 8(10): 14941510. doi: https://doi.org/10.20546/ijcmas.2019.810.175 